\title{
Experimental Study on Optimization of Physical Education Teaching Mode to Promote College Students' Social Development
}

\author{
Wang Zhanlong \\ Department of physical education of Hebei University Of Science and Technology, Hebei Shijiazhuang China \\ (bigdragon1972@163.com )
}

\begin{abstract}
According to the development trend and the current teaching mode of physical education teaching requirements, we optimized the construction of multiple teaching modes, through the contrast experiment for a year of study,. The results show that: optimizing the teaching mode can better meet the psychological needs; optimizing the teaching mode to improve students' ability of social adaptation. Due to the small sample size, short experimental time, remains to be further optimal effect of teaching mode, and gradually improve after the promotion.
\end{abstract}

Keywords - teaching mode, optimization of structure, psychological needs, social adaptation ability

\section{优化体育教学模式促进大学生社会性发展的实验研究}

\author{
王占龙 \\ 河北科技大学体育部 中国河北石家庄
}

\begin{abstract}
摘 要 根据体育教学模式发展趋势和当前教学要求, 我们对多种教学模式进行了优化构建, 通过一年的对比实验研究。结果表明: 优化教学模式能够更好的满足学生心理需求; 优化教学模式提高了学生社会适应能力。由于实验样本较小, 实验时间短, 优化教学模 式效果还有待进一步检验，逐步完善后进行推广。
\end{abstract}

关键词 教学模式, 优化构建, 心理需求, 社会适应能力

许多调查表明, 我国大学生心理健康水平正在下降, 心理问题相当普遍。如何促进大学生心理健康提高社会适 应力也是体育教学的主要目标, 学校体育促进学生心理健 康和社会性发展在理念上已有了基本的认同, 缺乏的是对 学校体育促进心理健康和社会性发展的机制的科学研究, 更缺乏将理念转化为实践的中介, 比如专门的体育教材与 体育教学模式。因此, 我们提出了优化体育教学模式促进 大学生社会性发展的构想, 并对这一构想进行了实验研究。

\section{1. 研究方法}

1.1 文献资料法: 查阅国内外有关教育理论等方面的书籍、 文献资料，为本文的研究提供可靠理论依据。

1.2 实验法: 选定河北科技大学 2011 级篮球选项班学生作 为实验对象, 随机抽取实验班 4 个班, 参加学生 140 名;
对照班 4 个班, 参加学生 142 名; 进行一学年的教学实验。

1.3 问卷调查法: 结合本研究的内容和目的, 心理健康状 况的调查采用了 《S C L-90 身心症状自评量表》, 社会 适应能力水平的调查采用《社会适应能力诊断量表》, 共 发放问卷 1138 份, 剔除无效问卷得到有效问卷 1107 份, 有效问卷回收率为 $97.3 \%$ 。

1.4 数理统计法: 采用 SPSS 统计软件对实验数据进行统计 处理。

\section{2. 研究结果与分析}

2.1 优化教学模式构建的理论基础

教学模式是在某一种特定教学理论思想指导下的, 相 对稳定而具体的教学活动结构, 学习和借鉴科学的、比较 
成熟的教学模式, 有助于改进教学, 提高教学质量。而对 于体育课程教学来说, 任何教学模式都有其特点, 都是对 体育教学规律的个别的、近似的、不完善的反映, 都有其 局限性, 但它们要完成的教育目标和任务是相近的、趋于 统一的。将多种体育教学模式的教学原理、指导思想、具 体教学策略和构成要素进行有机的融合和归纳, 使之能够 取长补短, 相互补益, 并在体育教学实践中加以灵活运用, 不断修改, 逐步完善。学习模式、研究模式、创新模式。 从而更加全面而完善地实现体育课程教学目标, 这种“优 化”的思想也是符合体育教学改革发展趋势的。

\section{2 优化教学模式的构建}

根据体育教学模式发展趋势和当前教学要求, 我们对 满足个体交往的小群体教学模式、拓宽教学空间的一体化 教学模式以及充分发挥学生主体性的主动学习教学模式进 行了优化。

为了淡化成绩评价中的甄别、选拔功能, 将考核评价 确定的最终考核成绩实行等级评价制。即: 将成绩评价中 的百分制转换为优 (90 100 分)、良(75 89 分)、及格 (60 74 分)、不及格 (60 分以下) 四个等级。

表 1 优化教学模式组织形式

\begin{tabular}{|c|l|l|l|}
\hline & \multicolumn{1}{|c|}{ 课前预习 } & \multicolumn{1}{c|}{ 课堂教学 } & \multicolumn{1}{c|}{ 课外锻炼 } \\
\hline 形式 & \multicolumn{1}{|c|}{ 以学生自主学习为主。 } & 集体或小组自主合作练习为主。 & 多种形式自主锻炼, 小组合作练习。 \\
\hline 要求 & $\begin{array}{l}\text { 使学生了解教材内容, 懂得运动 } \\
\text { 的原理和价值 }\end{array}$ & $\begin{array}{l}\text { 培养学生学习的兴趣, 使他们学会 } \\
\text { 练习的方法, 掌握技术技能及相关 } \\
\text { 知识。 }\end{array}$ & $\begin{array}{l}\text { 提高自我学习, 自我锻炼能力, 以的适应能力, 为终身体育打 } \\
\text { 下良好的基础。 }\end{array}$ \\
\hline 操作过程 & $\begin{array}{l}\text { 通过对教材的预习, 影视传媒、 } \\
\text { 电化教材的观摩, 场地器材的准 } \\
\text { 备等形式做好学习前的准备。 }\end{array}$ & $\begin{array}{l}\text { 召强对学生的学法指导, 通过典型 } \\
\text { 知识、基本技术的理解和掌握。 }\end{array}$ & $\begin{array}{l}\text { 学会在教师的指导下制定自我锻炼 } \\
\text { 的计划, 并付诸实施, 参加各种游 } \\
\text { 成功和进步的喜悦。 }\end{array}$ \\
\hline
\end{tabular}

表 2 优化教学模式的教学评价构建

\begin{tabular}{|c|c|c|c|c|}
\hline & 定量评价 40\% & 学生自评 $20 \%$ & 小组评价 $20 \%$ & 教师评价 $20 \%$ \\
\hline 内容 & 体能、技能、理论知识 & $\begin{array}{l}\text { 学习态度、情意表现合 } \\
\text { 作精神、进步幅度 }\end{array}$ & $\begin{array}{l}\text { 学习态度、情意表现、合作 } \\
\text { 精神、进步幅度 }\end{array}$ & $\begin{array}{l}\text { 学习态度、情意表现 } \\
\text { 合作精神、进步幅度 }\end{array}$ \\
\hline 形式 & $\begin{array}{l}\text { 对体育知识、技术和战 } \\
\text { 术运用能力和身体素质 } \\
\text { 进行评定。 }\end{array}$ & $\begin{array}{l}\text { 对自己的学习效果、努 } \\
\text { 力程度和心理感受等进 } \\
\text { 行评价 }\end{array}$ & $\begin{array}{l}\text { 班组同学根据该生实际表 } \\
\text { 现, 对照标准、全面衡量, } \\
\text { 进行小组评价。 }\end{array}$ & $\begin{array}{l}\text { 根据学生的个体状况对锻 } \\
\text { 炼和学习提出具体、合理 } \\
\text { 的改进建议。 }\end{array}$ \\
\hline 操作过程 & $\begin{array}{l}\text { 教师组织, 体委和组长 } \\
\text { 协助, 随堂测试。 }\end{array}$ & $\begin{array}{l}\text { 由教师统一安排, 学生 } \\
\text { 自行填写, 教师保管, } \\
\text { 年终汇总。 }\end{array}$ & $\begin{array}{l}\text { 由班组同学对照标准、全面 } \\
\text { 衡量, 进行小组评价。 }\end{array}$ & $\begin{array}{l}\text { 教师根据自己平时积累的 } \\
\text { 资料, 综合分析后进行评 } \\
\text { 价。 }\end{array}$ \\
\hline
\end{tabular}

\section{3 优化教学模式对心理健康的影响与分析}

通过实验组和对照组前后 S C L - 90 量表因子均分 (表 3, 4) 比较: 实验组学生心理素质显著提高, 对照组学生 无明显变化, 个别指标有下降趋势, 这表明新的教学模式 对增进学生心理健康有良好的效果。原因是: 优化教学模 式尊重学生的自主和自律, 在教学组织上多采用最大限度 地发挥学生主动性、积极性的个人自主学习和集体合作的
小组学习。有利于激发学生学习兴趣, 增强学生挑战和战 胜困难的勇气和能力, 磨练了意志品质; 有利于加强学生 之间和师生之间的交流, 使学生人际交往范围扩大, 人际 关系得到改善, 能够更好的满足学生心理需求。对照组学 生各因子得分变化不大, 其中强迫、焦虑、精神病性因子 得分较以前呈上升趋势。这表明, 正常体育课教学对提高 大学生心理素质效果不好, 值得社会关注。 
表 3 对照组实验前后前后 S C L -90 量表因子均分

\begin{tabular}{|c|c|c|c|c|}
\hline \multirow{2}{*}{ 因子 } & \multicolumn{4}{|c|}{ 对照组 $(\mathrm{N}=142)$} \\
\cline { 2 - 5 } & $\mathrm{X} \pm \mathrm{S}($ 前 $)$ & $\mathrm{X} \pm \mathrm{S}($ 后 $)$ & $|\mathrm{t}|$ & $\mathrm{P}$ \\
\hline 躯体化 & $1.32 \pm 0.32$ & $1.32 \pm 0.34$ & 0.07 & $>0.05$ \\
\hline 强迫 & $1.76 \pm 0.60$ & $1.85 \pm 0.54$ & 1.16 & $>0.05$ \\
\hline 人际关系 & $1.86 \pm 0.48$ & $1.77 \pm 0.48$ & 1.72 & $>0.05$ \\
\hline 抑郁 & $1.65 \pm 0.40$ & $1.61 \pm 0.40$ & 0.51 & $>0.05$ \\
\hline 焦虑 & $1.53 \pm 0.36$ & $1.56 \pm 0.37$ & 0.56 & $>0.05$ \\
\hline 敌意 & $1.51 \pm 0.41$ & $1.38 \pm 0.29$ & 1.92 & $>0.05$ \\
\hline 恐怖 & $1.33 \pm 0.30$ & $1.32 \pm 0.32$ & 0.30 & $>0.05$ \\
\hline 妄想 & $1.83 \pm 0.56$ & $1.76 \pm 0.54$ & 0.97 & $>0.05$ \\
\hline 精神病性 & $1.44 \pm 0.34$ & $1.45 \pm 0.33$ & 0.49 & \\
\hline
\end{tabular}

表 4 实验组实验前后前后 S C L -90 量表因子均分

\begin{tabular}{|c|c|c|c|c|}
\hline \multirow{2}{*}{ 因子项目 } & \multicolumn{4}{|c|}{ 实验组 $(\mathrm{N}=140)$} \\
\cline { 2 - 5 } & $\mathrm{X} \pm \mathrm{S}$ 前 & $\mathrm{X} \pm \mathrm{S}$ 后 & $|\mathrm{t}|$ & $\mathrm{P}$ \\
\hline 躯体化 & $43 \pm 0.39$ & $1.37 \pm 0.33$ & 1.69 & $>0.05$ \\
\hline 强迫 & $1.89 \pm 0.65$ & $1.80 \pm 0.60$ & 2.44 & $<0.05$ \\
\hline 人际关系 & $1.89 \pm 0.62$ & $1.72 \pm 0.62$ & 2.91 & $<0.01$ \\
\hline 抑郁 & $1.68 \pm 0.53$ & $1.44 \pm 0.37$ & 2.12 & $<0.05$ \\
\hline 焦虑 & $1.47 \pm 0.22$ & $1.37 \pm 0.18$ & 2.36 & $<0.05$ \\
\hline 敌意 & $1.55 \pm 0.35$ & $1.48 \pm 0.34$ & 1.70 & $>0.05$ \\
\hline 恐怖 & $1.40 \pm 0.46$ & $1.24 \pm 0.27$ & 2.01 & $>0.05$ \\
\hline 妄想 & $1.67 \pm 0.51$ & $1.45 \pm 0.44$ & 3.01 & $<0.01$ \\
\hline 精神病性 & $1.45 \pm 0.36$ & $1.38 \pm 0.29$ & 1.89 & $>0.05$ \\
\hline
\end{tabular}

\section{4 优化教学模式对学生社会适应能力的影响与分析}

社会适应能力是指个体为了适应社会生活环境而调整 自己的行为习惯或态度过程的能力。社会适应能力包括人 的自我心理调节能力、辨别区分事物能力、与人沟通能力、 应变能力、理解能力和独立处理事务等方面的能力。

实验结果表明: 实验班学生的社会适应能力明显强于 对照班学生。成因分析: 实验班大多数体育活动是在群体 中展开的, 人际间的互动十分频繁, 为学生提供了人际交 往的空间, 培养了学生人际交往能力; 实验班中小组间的 分工合作增加了团队的凝聚力, 小组间的竞赛加强了各小 组荣辱与共的感情, 培养了学生竞争合作的意识, 使学生 学会善待他人, 尊重他人的人格和意见, 与他人友好相处 合作共事, 从而促使学生最终形成独立自主而又乐于与他
人合作的精神与能力, 提高了社会适应能力。

表 5 实验后实验班、对照班学生社会适应能力调查统计表

\begin{tabular}{|c|r|r|r|r|l|}
\hline \multirow{2}{*}{ 分数 } & \multicolumn{2}{|c|}{ 对照班 } & \multicolumn{2}{|c|}{ 实验班 } & \multirow{2}{*}{\begin{tabular}{c} 
适应 \\
\cline { 2 - 5 }
\end{tabular}} \\
\cline { 2 - 5 } 人数 & 比率 & \multicolumn{1}{c|}{ 人数 } & 比率 & 能 \\
\hline $38 \sim 40$ & 17 & 12 & 25 & 18 & 很强 \\
\hline $34 \sim 37$ & 21 & 15 & 31 & 22 & 良好 \\
\hline $29 \sim 33$ & 50 & 35 & 57 & 41 & 一般 \\
\hline $23 \sim 28$ & 43 & 30 & 21 & 15 & 较差 \\
\hline 22 以下 & 11 & 8 & 6 & 4 & 很差 \\
\hline
\end{tabular}




\section{3. 结论与建议}

3.1 优化教学模式能够更好的满足学生心理需求。

优化教学模式能够加强学生之间和师生之间的交 流, 使学生人际交往范围扩大, 人际关系得到改善, 增 强了学生挑战和战胜困难的勇气和能力, 磨练了意志品 质。能够更好的满足学生心理需求, 有利于学生社会性 发展目标的实现。

\section{2 优化教学模式提高了学生社会适应能力。}

优化教学模式培养了学生人际交往能力和竞争合作 的意识, 促使学生最终形成独立自主而又乐于与他人合 作的精神与能力, 提高了学生社会适应能力。

\section{3 优化教学模式还有待进一步完善。}

教学实验是一个复杂的过程, 本研究中通过实验控 制尽量做到了实验班与对照班在师资、场地器材、课外 练习时间等因素上大致相同。但是实验中还有许多不完
善和不尽如人意的环节, 还需要进一步深入研究和实践。 优化教学模式作为一种新兴的教学模式在摸索和总结的 过程中, 也经过某些方面的论证和分析, 但总的说来, 理论基础的坚实性还不够, 教学模式的系统性、科学性 尚有待于进一步探讨, 使之渐致完善。

\section{参考文献(References)}

[1] Zheng Richang, psychological diagnosis. Ji'nan: Shandong Education Press, 1999 (In Chinese)

[2] Pan Ming, Liu Biaohu, the school sports health promotion of on students' mental health and social. Physical education, 2006, ( 1 ): 56 (In Chinese)

[3] Ji Liu, physical education and health curriculum and teaching theory. Zhejiang Education Publishing House, 2003, 8 (In Chinese)

[4] Zheng Richang, psychological diagnosis, Ji'nan: Shandong Education Press, 1999 (In Chinese)

[5] Xiqian, learning evaluation Journal of physical education and sports in Ceng Huaiguang, 2001, ( 11 ) $80-83$ (In Chinese) 